\title{
Satellite-observed variability and trend in sea-ice extent, surface temperature, albedo and clouds in the Arctic
}

\author{
Josefino C. Comiso \\ Oceans and Ice Branch, NASA Goddard Space Flight Center, Code 971, Greenbelt, MD 20771, U.S.A.
}

\begin{abstract}
Recent observations of a decreasing ice extent and a possible thinning of the ice cover in the Arctic make it imperative that detailed studies of the current Arctic environment are made, especially since the region is known to be highly sensitive to a potential change in climate. A continuous dataset of microwave, thermal infrared and visible satellite data has been analyzed for the first time to concurrently study in spatial detail the variability of the sea-ice cover, surface temperature, albedo and cloud statistics in the region from 1987 to 1998. Large warming anomalies during the last four years (i.e. 199598) are indeed apparent and spatially more extensive than previous years. The largest surface temperature anomaly occurred in 1998, but this was confined mainly to the western Arctic and the North American continent, while cooling occurred in other areas. The albedo anomalies show good coherence with the sea-ice concentration anomalies except in the central region, where periodic changes in albedo are observed, indicative of interannual changes in duration and areal extent of melt ponding and snow-free ice cover. The cloud-cover anomalies are more difficult to interpret, but are shown to be well correlated with the expected warming effects of clouds on the sea-ice surface. The results from trend analyses of the data are consistent with a general warming trend and an ice-cover retreat that appear to be even larger during the last dozen years than those previously reported.
\end{abstract}

\section{INTRODUCTION}

The Arctic sea-ice cover has been on the decline at the rate of 2.5-3.0\% per decade in recent years (Bjørgo and others, 1997; Cavalieri and others, 1997; Parkinson and others, 1999). A possible thinning of Arctic sea ice has also been reported in submarine-based studies (Wadhams, 1990; Rothrock and others, 1999). Meanwhile, trend analysis of surface temperature data from longer time periods recorded by meteorological stations around the world also indicates a $0.6^{\circ} \mathrm{C}$ rise in global temperature during the last 100 years (Jones and others, 1999) and local warming in Arctic regions exceeding $0.5^{\circ} \mathrm{C}$ per decade warming during the period 1961-90 (Chapman and Walsh, 1993). Globally, the 1990s is considered the warmest decade, while 1998 was observed as the warmest year during the last century. A detailed examination of these phenomena is important because the Arctic has been cited as a region that is especially sensitive to climate change (Manabe and Stouffer, 1992; Alley, 1995).

The objective of this study is to gain new insights into the apparently changing Arctic environment through analysis of large-scale seasonal and interannual variabilities of various Arctic parameters, including sea-ice extent, surface temperature, albedo and cloud cover. It is also of strong interest to find out where the anomaly patterns are located, how persistent they are and how the different parameters are affected by each other. Satellite passive-microwave data have been utilized to obtain spatially detailed and continuous coverage of the Arctic region (Gloersen and others, 1992). However, currently available data on surface temperature, albedo, cloud cover and other parameters in the region are at best very spotty and lack spatial coverage. In this study, visible and infrared channels of the U.S. National Oceanic and Atmospheric Administration (NOAA) Advanced Very High Resolution Radiometer (AVHRR) data have been processed to obtain a continuous dataset of clouds, albedo and surface temperatures from 1987 through 1998. This is the first time that such co-registered datasets of these parameters have been put together and analyzed. The assembly of these datasets provides a means to examine expected feedback effects, the relationships among the various Arctic variables and teleconnections with low-latitude regions. They are also useful as input and validation to existing climate models and for heatflux and mass-balance studies. Although the record length of the data that have so far been processed is only 12 years, it is a 12 year period of considerable changes in the Arctic environment. The record is also a good complement to the Arctic vertical profile pathfinder dataset (Francis and Schweiger, 2000) derived from the TIROS Operational Vertical Sounder (TOVS) at a resolution of $100 \mathrm{~km}$ by $100 \mathrm{~km}$.

\section{ANALYSIS OF SATELLITE DATA}

The two satellite sensors that have provided long-term and consistent datasets over the polar regions have been the passive-microwave sensors and the AVHRRs. Passivemicrowave data provide comprehensive day/night, almost all-weather surface characterization of the sea-ice cover, while infrared and visible data provide the only means to obtain synoptic large-scale surface temperature and albedo, respectively. To assemble a long dataset, data from several satellite passive-microwave sensors have to be put together. For example, the Scanning Multichannel Microwave Radiometer (SMMR) data from 1979 to 1987 have to be combined 
Yearly Average Ice Concentrations
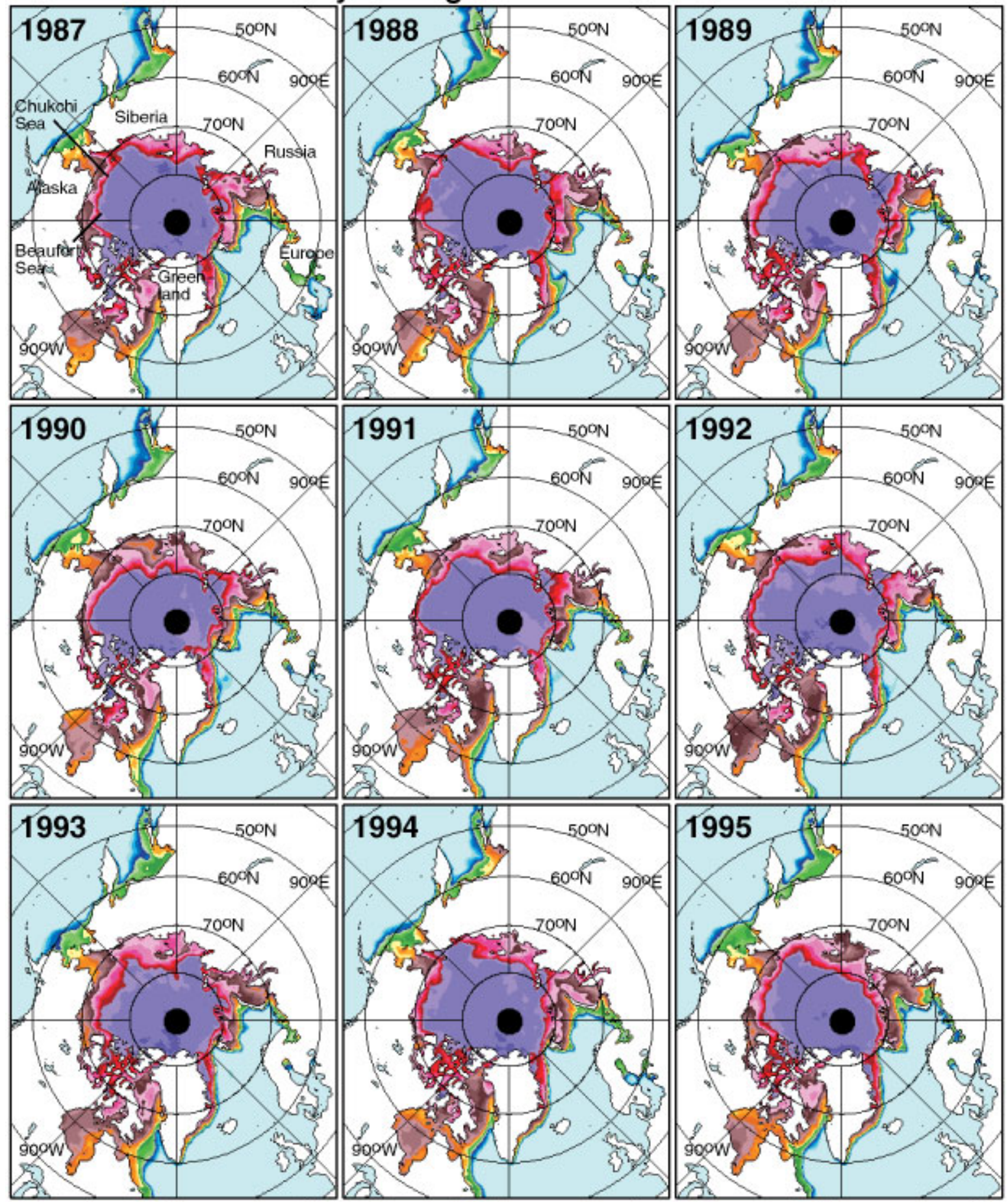

$100 \%$

$98 \%$

$94 \%$

$90 \%$

$86 \%$

$82 \%$

$78 \%$

$\mathbf{7 4} \%$

$70 \%$

$66 \%$

$62 \%$

$58 \%$

$\mathbf{5 4} \%$

$50 \%$

$46 \%$

$42 \%$

$38 \%$

$34 \%$

$30 \%$

$26 \%$

$22 \%$

$18 \%$

$14 \%$

$10 \%$
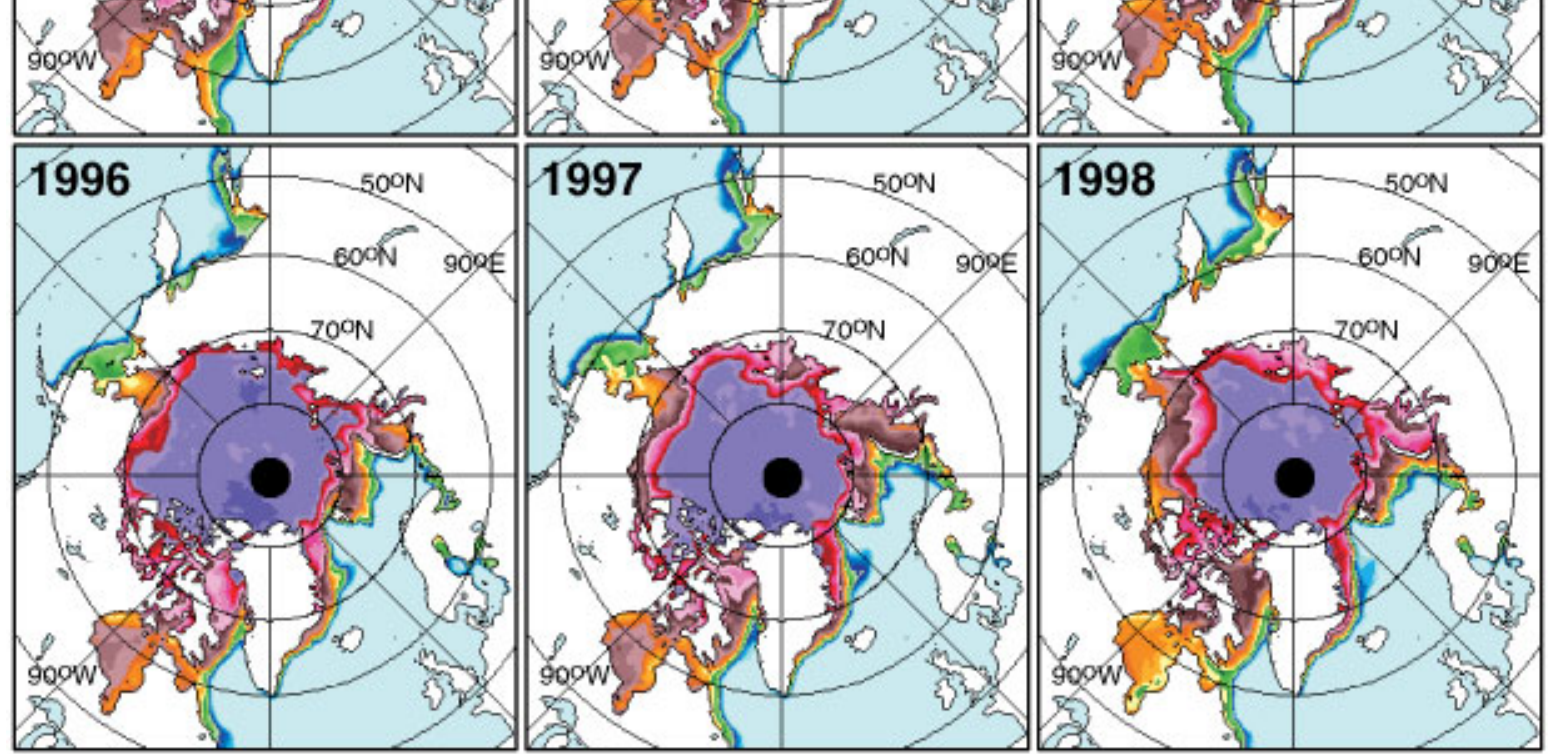

$<8 \%$
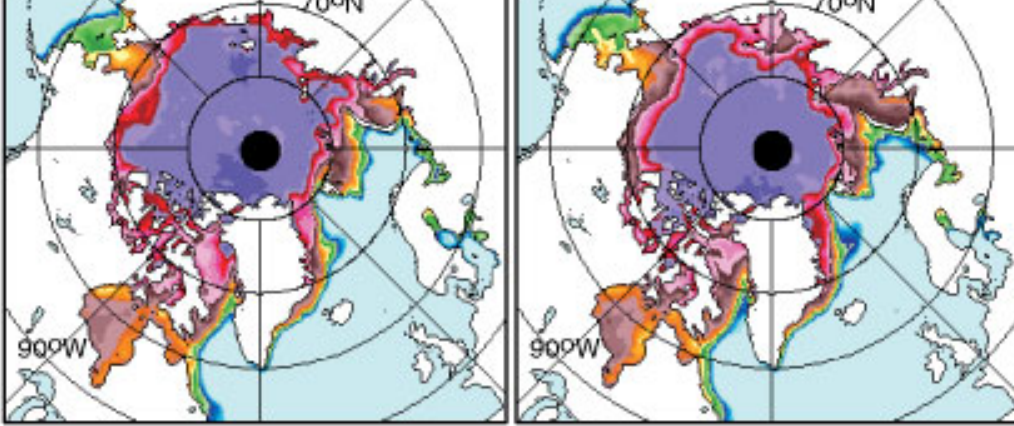

Fig. 1. Color-coded yearly-average sea-ice concentration maps in the Arctic, 1987-98. The ice concentrations were derived from satellite passive-microwave data using the Bootstrap algorithm (Comiso, 1995). 


\section{Anomalies in Yearly Ice Concentrations}
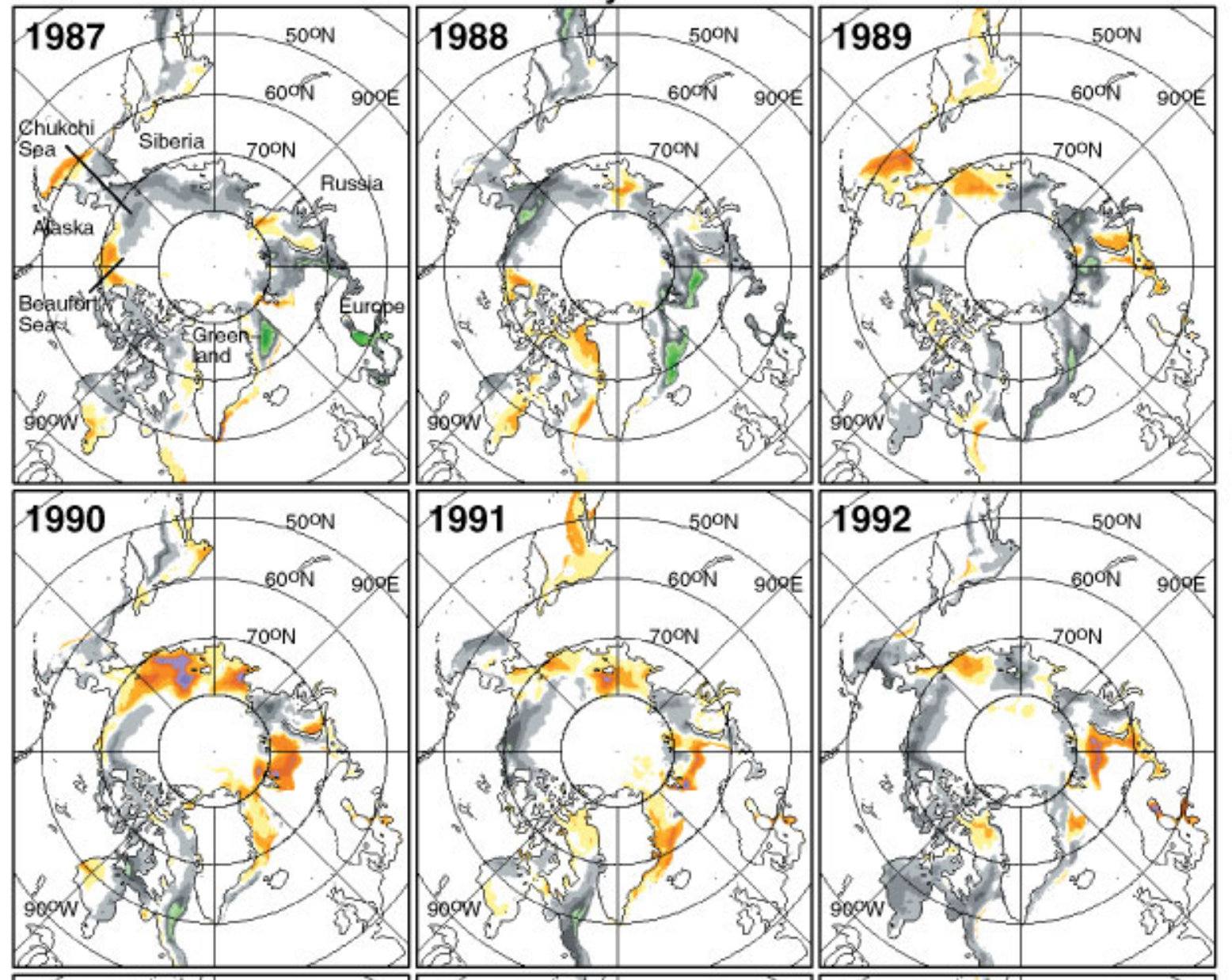

$55.0 \%$

$\mathbf{5 0 . 0} \%$

$45.0 \%$

$40.0 \%$
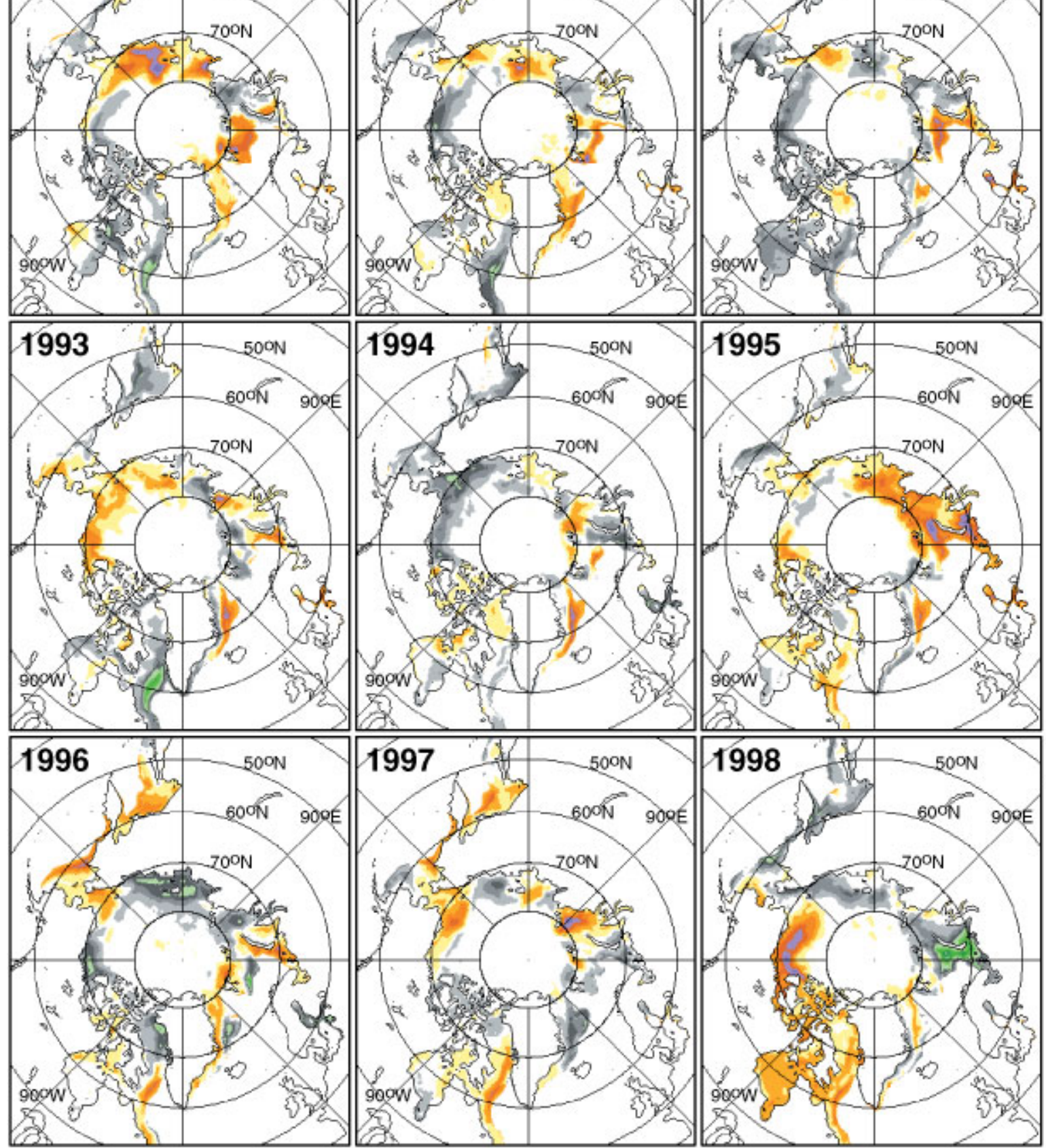

$35.0 \%$

$30.0 \%$

$25.0 \%$

$20.0 \%$

$15.0 \%$

$10.0 \%$

$5.0 \%$

$0.0 \%$

$-5.0 \%$

$-10.0 \%$

$-15.0 \%$

$-20.0 \%$

$-25.0 \%$

$-30.0 \%$

$-35.0 \%$

$-40.0 \%$

$-45.0 \%$

$-50.0 \%$

$-\mathbf{5 5 . 0} \%$

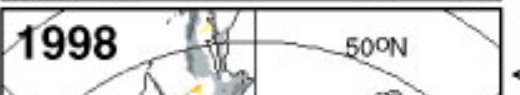

$<-57.5 \%$

\begin{tabular}{|l|}
\hline \\
\hline \\
\hline \\
\hline \\
\hline \\
\hline \\
\hline \\
\hline \\
\hline \\
\hline \\
\hline
\end{tabular}



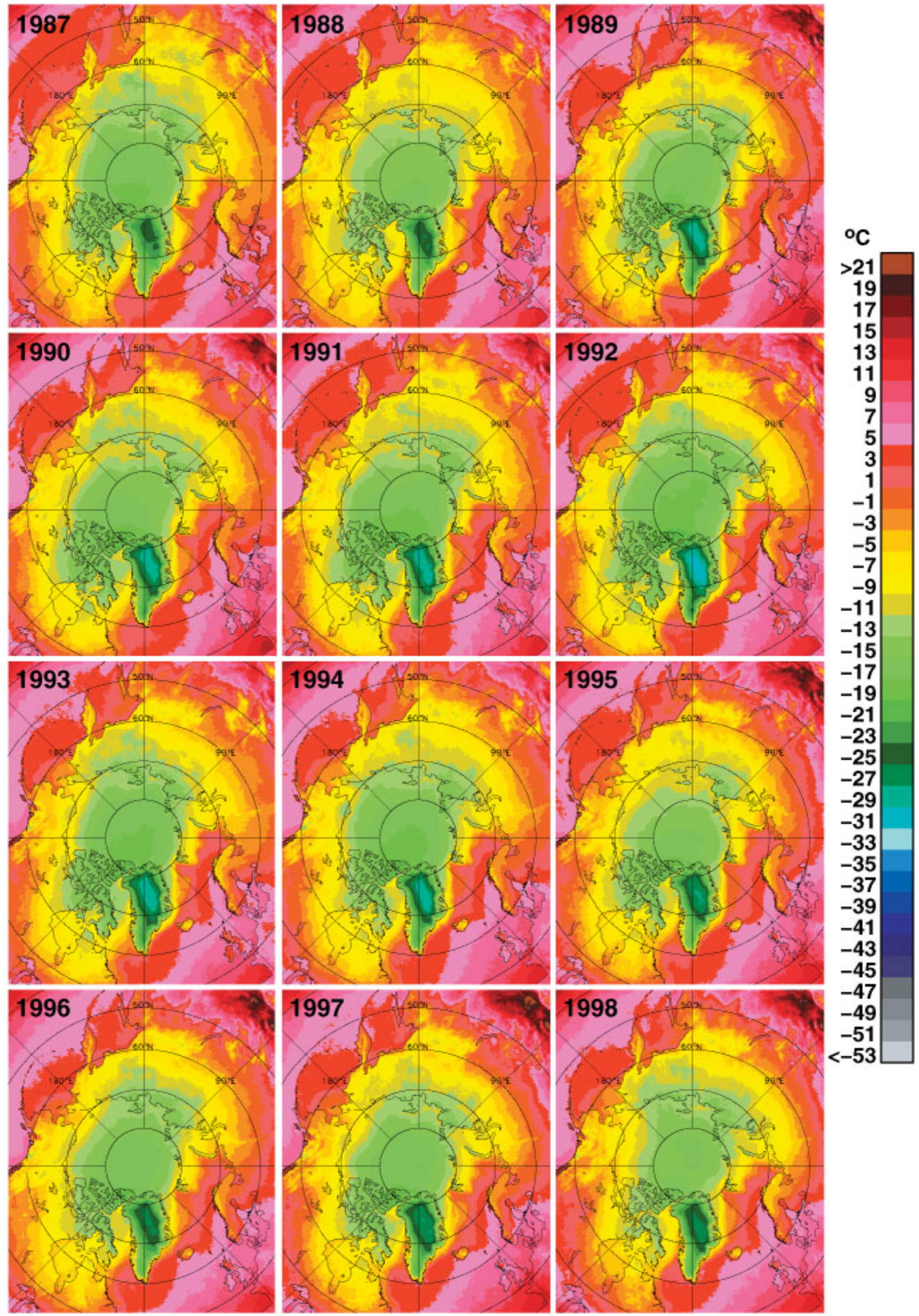

Fig. 4. Color-coded yearly-average surface temperature maps derived from AVHRR thermal infrared data in the Arctic, 1987-98. 


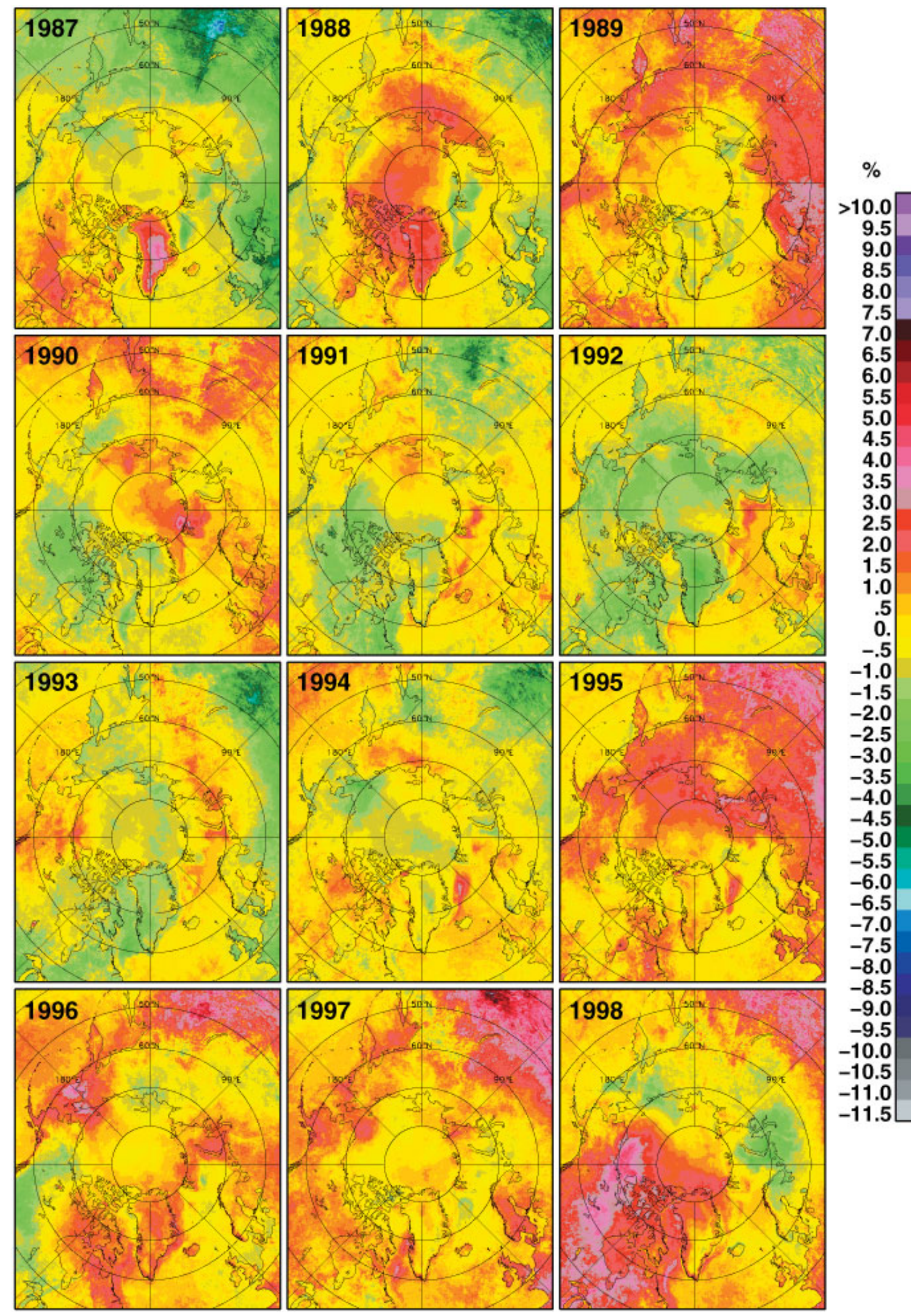

Fig. 5. Color-coded anomalies of yearly surface temperatures in the Arctic, 1987-98. 

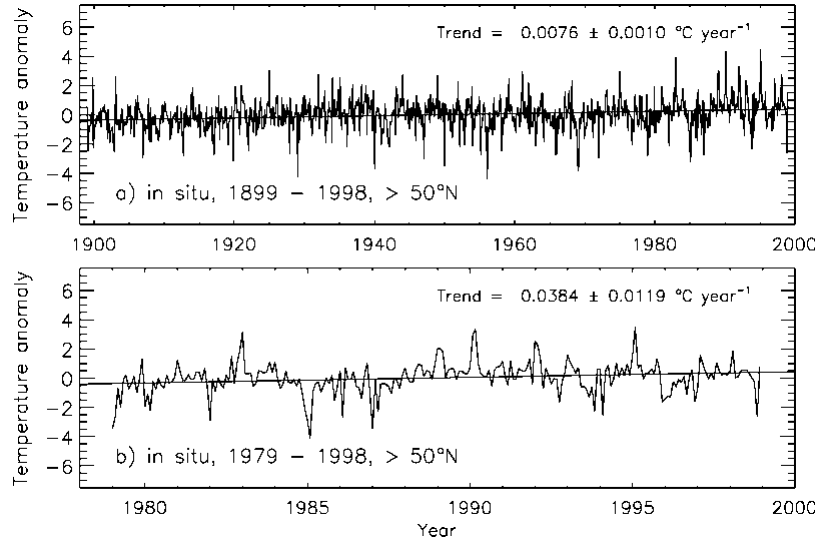

Fig. 3. Monthly temperature anomalies observed from meteorological stations, (a) 1899-1998 and (b) 1979-98. The station data were compiled by fones and others (1999).

with those of several Special Scanning Microwave Imager (SSM/I) data (i.e. F8-F13) from 1987 to 1998 to form a relatively long-term dataset. Likewise, the AVHRR dataset is also a compilation of data from several satellite sensors (i.e. NOAA-7 to NOAA-14). Each sensor has been calibrated using established calibration techniques, but slight adjustments were made for each sensor through the use of calibration coefficients derived from regressions of sensor data with in situ data. The use of the latter minimizes errors associated with the utilization of pre-launch calibration parameters and provides better consistency in the time series for improved interpretation of the interannual variability of the geophysical parameters. The AVHRR data have been mapped in a polar stereographic grid similar to that used for passivemicrowave data but at a higher resolution (i.e. 6.25 by $6.25 \mathrm{~km}^{2}$ instead of the 25 by $25 \mathrm{~km}^{2}$ used for passive-microwave data). The techniques used in the retrieval of surface and cloud parameters from the data have been discussed previously (Steffen and others, 1993), while the specific technique for the dataset used in this study is discussed in Comiso (2000). In the following sections, we discuss the state of the Arctic during the last 12 years, as inferred from these datasets, with the emphasis on interannual changes but with some consideration of seasonal changes. In this paper, yearly anomaly maps are presented, which are generated by taking the difference between the yearly average and the 12 year average.

\section{Sea-ice concentration}

Sea-ice concentration maps in the Arctic region have been derived consistently since the advent of multi-frequency satellite passive-microwave data (Comiso, 1986; Gloersen and others, 1992). In the Arctic, ice concentration can be derived with uncertainties of 3-15\% depending on location and season (Comiso, 1995). The large seasonal variability in the ice cover is well known and usually dominates the temporal variability. To get an idea of how the ice cover has changed from one year to the next, yearly averages in ice concentration were generated (Fig. 1). The images consistently show highly concentrated ice in the central Arctic, and lower concentrations in the shelf regions, because in the latter the pixels have mainly open water in the summer and new or first-year ice during other seasons. However, large year-to-year changes are apparent near the continental borders, reflecting the dynamics associated with the Arctic ice cover. The ice cover in the peripheral seas is mainly seasonal ice and also shows significant variations from one year to another.

The year-to-year variability is better quantified in the anomaly maps of the yearly averages as presented in Figure 2. The grays and greens indicate anomalously high ice-concentration values, while the oranges, purples and reds indicate anomalously low values. During the last 12 years, the most remarkable change in the Arctic sea-ice cover probably occurred in 1998, when the largest open-water area in the western region, especially in the Beaufort Sea (i.e. adjacent to Alaska), was observed during the summer. The anomalously low values (oranges and purples) are shown to cover an area that includes Hudson Bay and Baffin Bay. In the eastern region, however, a positive anomaly, especially in the Barents Sea, is also apparent during the same year. This positive anomaly extended towards the western region and into the Okhotsk Sea. An almost opposite scenario is apparent in 1990, when the positive anomalies are in the western region and the negative anomalies are in the eastern region, suggesting that the anomalies move around the Arctic. The anomaly maps also indicate a very large negative change in the ice cover in the eastern region in 1995. The summer ice cover during this year was actually less extensive than in 1998, although the ice retreat in 1995 was not as apparent. The high ice-cover anomalies are generally in different places during different years. No single area can be identified as consistently gaining or losing ice cover. The magnitude of the anomalies, however, appears to vary with years, with the high negative ones occurring in later years, as in 1995 and 1998. This partly explains why the trend in the ice cover has been observed to be negative.

\section{Surface temperature}

Our analysis of surface air temperatures, using the set of meteorological-station data compiled by Jones and others (1999), but including only those located north of $50^{\circ} \mathrm{N}$, indicates a warming trend of $0.008 \pm 0.001 \mathrm{~K} \mathrm{a}^{-1}$ when the 100 year records are used (Fig. 3). The trend is even greater, at $0.038 \pm 0.009 \mathrm{~K} \mathrm{a}^{-1}$, when the records from the last 20 years for the same set of stations are used (Fig. 3). The large change in trend suggests a possible acceleration in the rate of increase in temperature during the last few years. Since there are only a few meteorological stations at high latitudes, it would be of interest to examine how this phenomenon is reflected on a large scale and for the entire Arctic region.

The yearly maps of surface temperatures derived from AVHRR data for the period 1987-98 are presented in Figure 4. As indicated earlier, the resolution of this dataset is 6.25 by $6.25 \mathrm{~km}^{2}$ which is much better than that of the pathfinder dataset (at 100 by $100 \mathrm{~km}^{2}$ ) described by Francis and Schweiger (2000). Comparison of the retrieved data with in situ measurements yielded an rms error for these temperatures that is generally $<3{ }^{\circ} \mathrm{C}$ and consistent with similar retrievals in the Antarctic (Comiso, 2000). As in the latter, the bias due to the warming (or cooling) effect of clouds was studied using in situ data, in this case the SHEBA dataset in the Arctic collected from October 1997 through September 1998. The cloud-masking bias is quantified for each month by taking the difference of the monthly average using the continuous dataset, and that when only the average of data during cloud-free conditions (as determined by AVHRR) is used. The results show a warm bias averaging about $0.1^{\circ} \mathrm{C}$ in the summer and a cold bias of about $0.4^{\circ} \mathrm{C}$ during the rest of the year. Such biases are well 

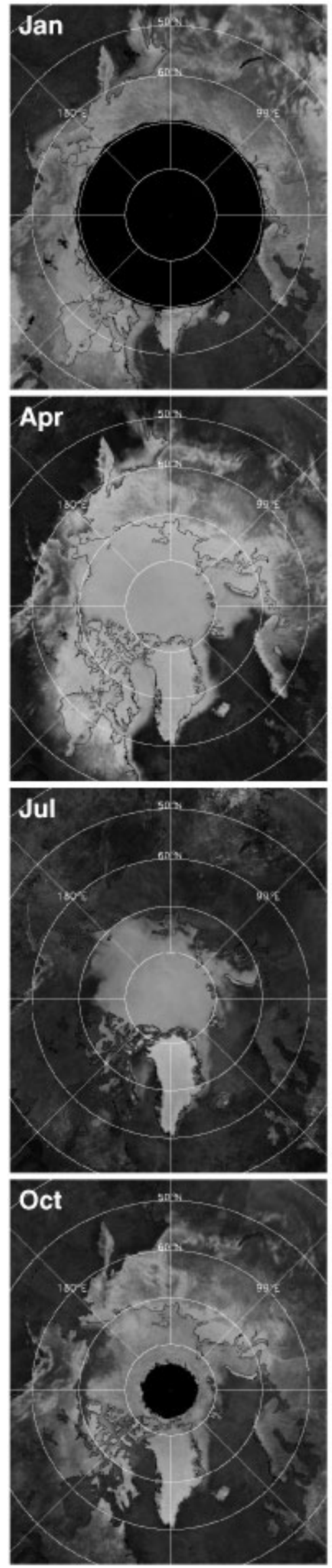
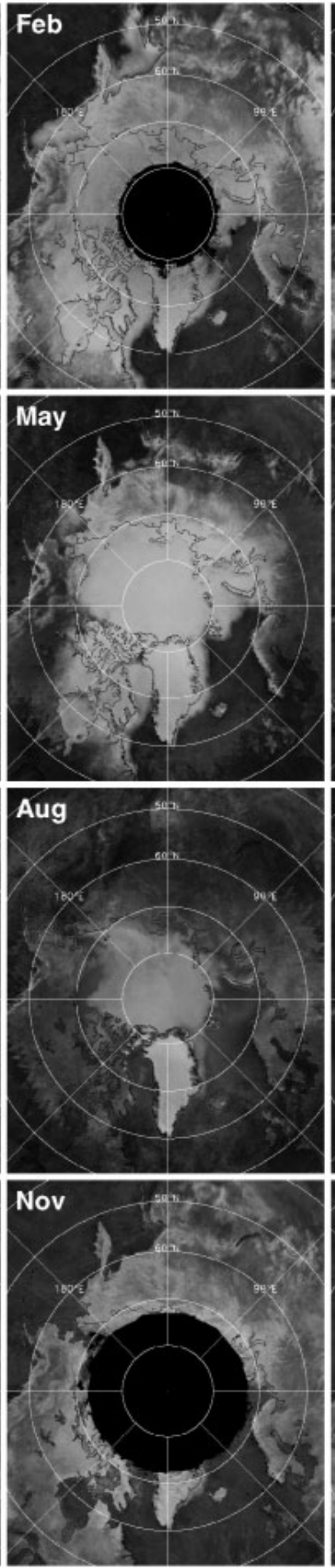

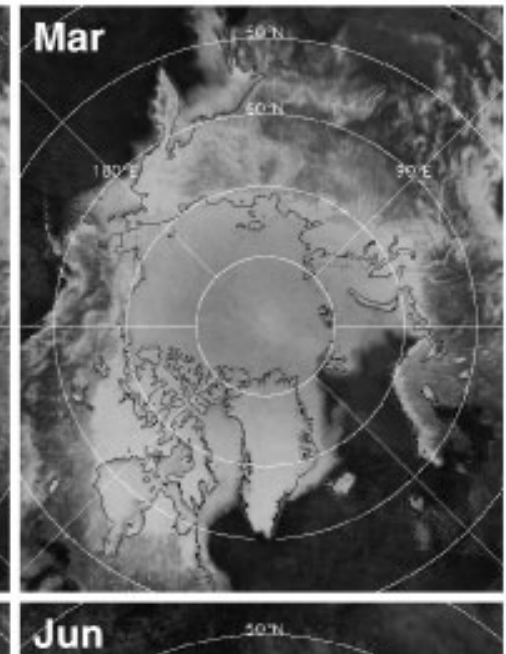

$\%$
100
96
92
88
84
80
76
72
68
64
60
56
52
48
44
40
36
32
28
24
20
16
12
8
4
0 


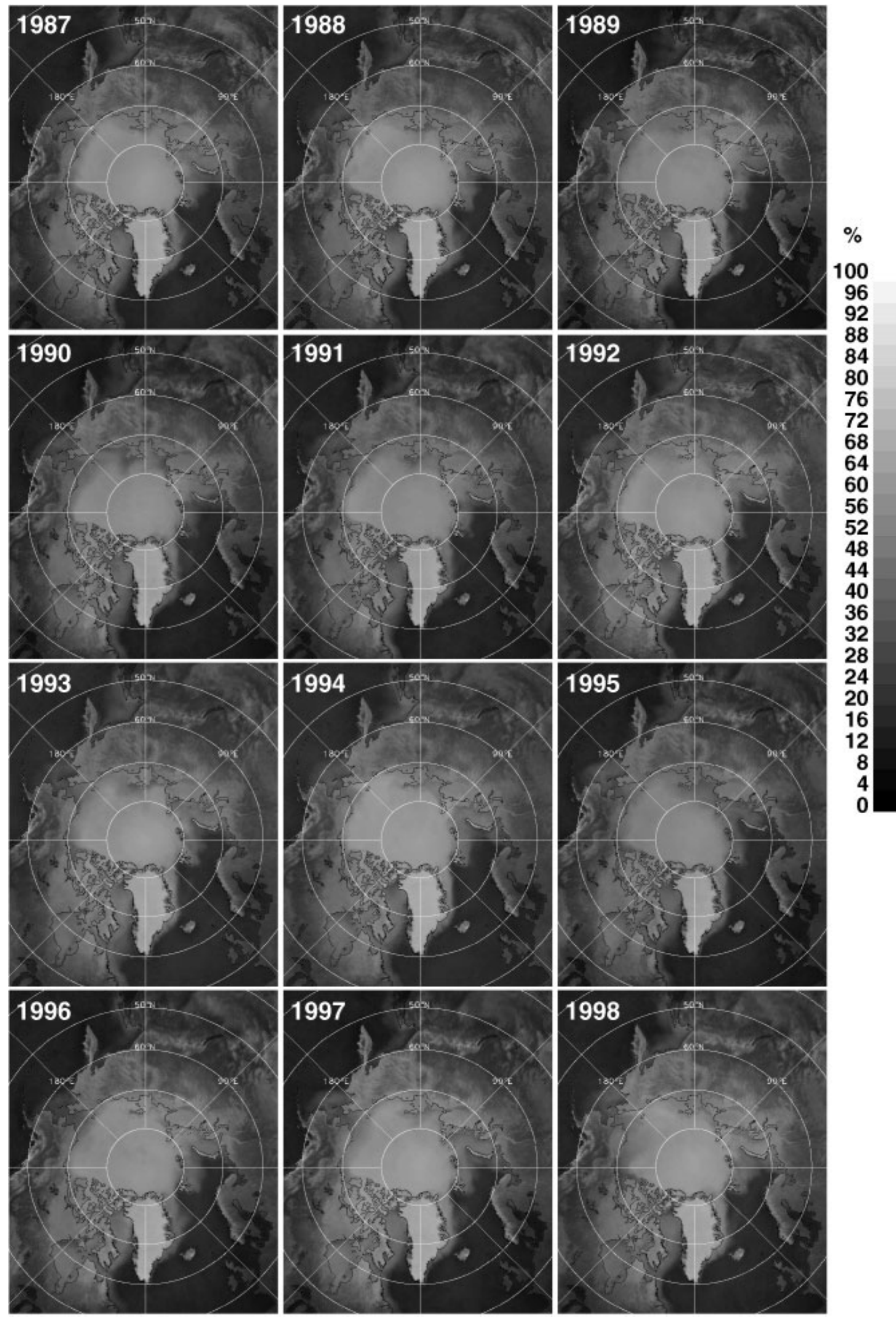

Fig. 7. Coded yearly-average albedo maps from AVHRR data in the Arctic, 1987-98. 

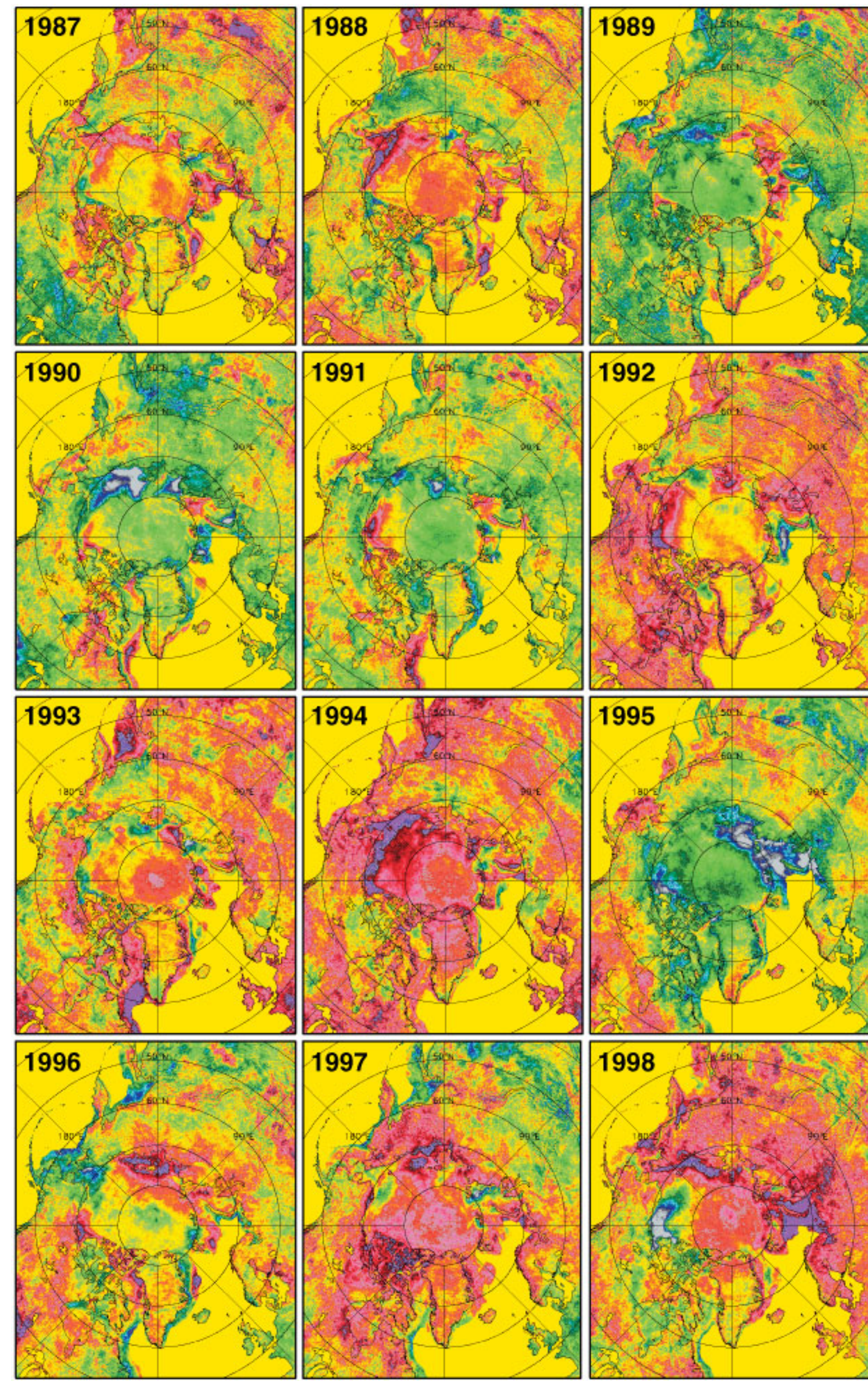

$\begin{array}{r}\multicolumn{1}{r}{\%} \\ >10.0 \\ 9.5 \\ 9.0 \\ 8.5 \\ 8.0 \\ 7.5 \\ 7.0 \\ 6.5 \\ 6.0 \\ 5.5 \\ 5.0 \\ 4.5 \\ 4.0 \\ 3.5 \\ 3.0 \\ 2.5 \\ 2.0 \\ 1.5 \\ 1.0 \\ .5 \\ 0 . \\ -.5 \\ -1.0 \\ -1.5 \\ -2.0 \\ -2.5 \\ -3.0 \\ -3.5 \\ -4.0 \\ -4.5 \\ -5.0 \\ -5.5 \\ -6.0 \\ -6.5 \\ -7.0 \\ -7.5 \\ -8.0 \\ -8.5 \\ -9.0 \\ -9.5 \\ -10.0 \\ -10.5 \\ -11.0 \\ -11.5 \\ \hline\end{array}$

Fig. 8. Color-coded anomalies of yearly albedo from AVHRR in the Arctic, 1987-98. 
within the margin of error in the retrieval of the AVHRR temperature data.

The general patterns of the temperature isotherms for the different years are shown to be very similar, but large interannual variabilities are apparent in some areas. The isotherms are shown to extend from the sea ice to the continental region, with no apparent boundary between the two regions, indicating no drastic changes in the atmospheric forcing from one region to another. The coldest region as observed from these yearly averages is always located in Greenland, although in mid-winter the monthly averages (not shown) show that this is not always the case. The next coldest region is the central Arctic, especially north of Greenland and the Queen Elizabeth Islands, but the monthly maps (not shown) indicate that parts of Eurasia are colder than this area during mid-winter. Year-to-year changes in these regions can be identified by the changes in the location and extent of the cold (green) areas.

The interannual variability in surface temperature is better quantified in the anomaly maps shown in Figure 5. These show the areas of the Arctic region where the most intense warming and cooling occur. They also show that the Arctic goes through phases of warming and cooling, as opposed to progressive (monotonic) increases in temperature. The warming in 1988-90 was followed by a cooling period in 1991-94 that may have been partly influenced by the Mount Pinatubo (Philippines) eruption in 1991. The period 1995-98 was again a warming period, with the warming in 1998 being the most intense but concentrated mainly on the North American side of the Arctic region. It should be noted that the large anomaly in the open-water area in 1998 (see Fig. 2) was not confined to the Beaufort Sea region, but is shown to be part of a heatwave that extended throughout Alaska and Canada. Greenland is also shown to be relatively warm during the period 1995-98, but not as warm as in 1987 and 1988.

\section{Albedo}

The albedo of snow- and ice-covered areas is generally high compared to that of open ocean. The energy and heat exchange between the surface and the atmosphere can thus be significantly altered by large anomalies in the snow and ice cover. The albedo of snow and ice is, however, not uniform and could vary considerably from one region to another and from one type of surface to another (Allison and others, 1993). Over sea-ice-covered areas, the albedo depends on the fraction of open water within the footprint of the sensor, the thickness of the ice, the thickness of its snow cover and the granularity or wetness of the surface. Sea-ice albedo is also affected by particles or sediments entrained during storms or resuspended from the seabed. These are exposed at the ice surface when the snow melts in spring and summer (Pfirman and others, 1990). Over land, the albedo of snow-covered areas depends on granularity and thickness of snow, the wetness of the surface, the slope of the terrain, and the area of snow-free surface and the vegetative cover within the footprint of the sensor.

The albedo presented in this study is just strictly the reflectivity of the surface as observed by the sensor at $0.6 \mu \mathrm{m}$ (channel 1) and corrected to account for changes in solar zenith angle. Other corrections, such as those for atmospheric aerosol and the anisotropic reflectance of snow and sea ice (Jin and Simpson, 1999) have not been implemented. Also, during mid-winter, there were no channel 1 data in some high-latitude areas because of darkness. The December and January maps have the biggest data loss on account of this factor. Taking these limitations into consideration, the data can be used to assess large-scale albedo distribution and its interannual variability in the Arctic region assuming similar influences by aerosol and surface anisotropy every year.

Monthly maps of albedo, as recorded by channel 1 throughout 1998, are shown in Figure 6. The black circular areas of varying diameters in the middle of the images for October-March correspond to no data, as indicated earlier. The maps show unique features, with high albedo in snowcovered areas (e.g. Siberia), that are persistent from one month to the next during the year. The persistence of these features indicates that they are surface features and that the cloud masking used in this study was reasonably effective. The monthly maps provide a sense of how rapidly the snow and sea-ice cover changes during the season. Over continental land areas, the patterns of snow cover are very well represented and are shown to be persistent (i.e. having high albedo) in some areas and sporadic in other areas. Over sea ice, intermediate values in albedo represent new ice or relatively low ice-concentration values, but in the summer they may represent melt-ponded and barren (snow-free) ice cover as well.

The yearly maps from 1987 to 1998, as shown in Figure 7, provide a means of assessing the overall interannual variability of the albedo in the entire Arctic region. Each yearly albedo map is generated by taking the average of the 12 monthly average data, with the missing data in winter not counted in the averaging. In the sea-ice region, it is apparent that the albedo in the perennial-ice region is higher than that of the seasonal-ice region, partly due to the latter area becoming ice-free (i.e. low albedo) during parts of the year. The slight difference allows for qualitative comparisons of the extents of the perennial and seasonal ice cover from one year to the next.

Although the major changes in albedo are the changes with season associated with the advance and retreat of the sea-ice and snow cover, it is the year-to-year changes in albedo that are needed to estimate interannual changes in heat and radiative budgets. The yearly anomaly maps, shown in Figure 8, provide a means to better assess overall changes from one year to another. In the sea-ice region, the changes are very similar to those of ice concentration and provide independent information since the ice-concentration maps were inferred from another sensor. The regions represented by greens and grays in the Arctic reflect anomalous retreats in the ice cover, while the reds and purples represent areas where the ice concentration was anomalously high during the year. In the continental areas, some periodic changes are apparent, with anomalously low albedos (or less snow) in 1989-91 followed by anomalously high albedos in 1992-94 and low in 1995. The pattern continues on through 1998, but the temporal changes were not as pronounced during the latter period.

\section{Gloud statistics}

The ability to accurately derive surface albedo and surface temperature depends on the ability to properly identify and mask the cloud-covered portion in the AVHRR images. Cloud masking is especially difficult in the polar regions because the reflectance and radiative characteristics of clouds are very similar to those of areas covered by snow and ice. 

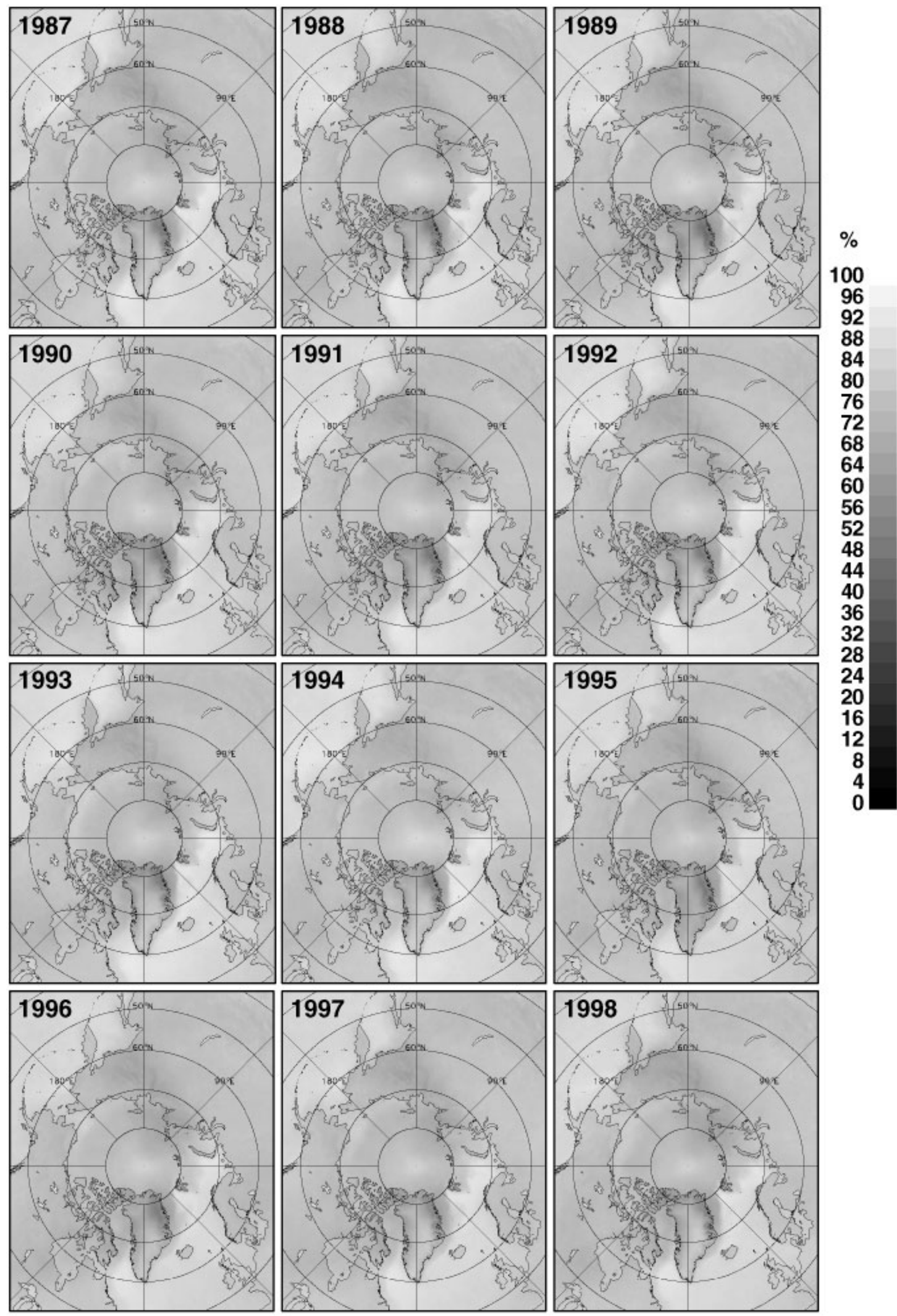

Fig. 9. Coded yearly-average cloud-cover statistics from AVHRR in the Arctic, 1987-98. 


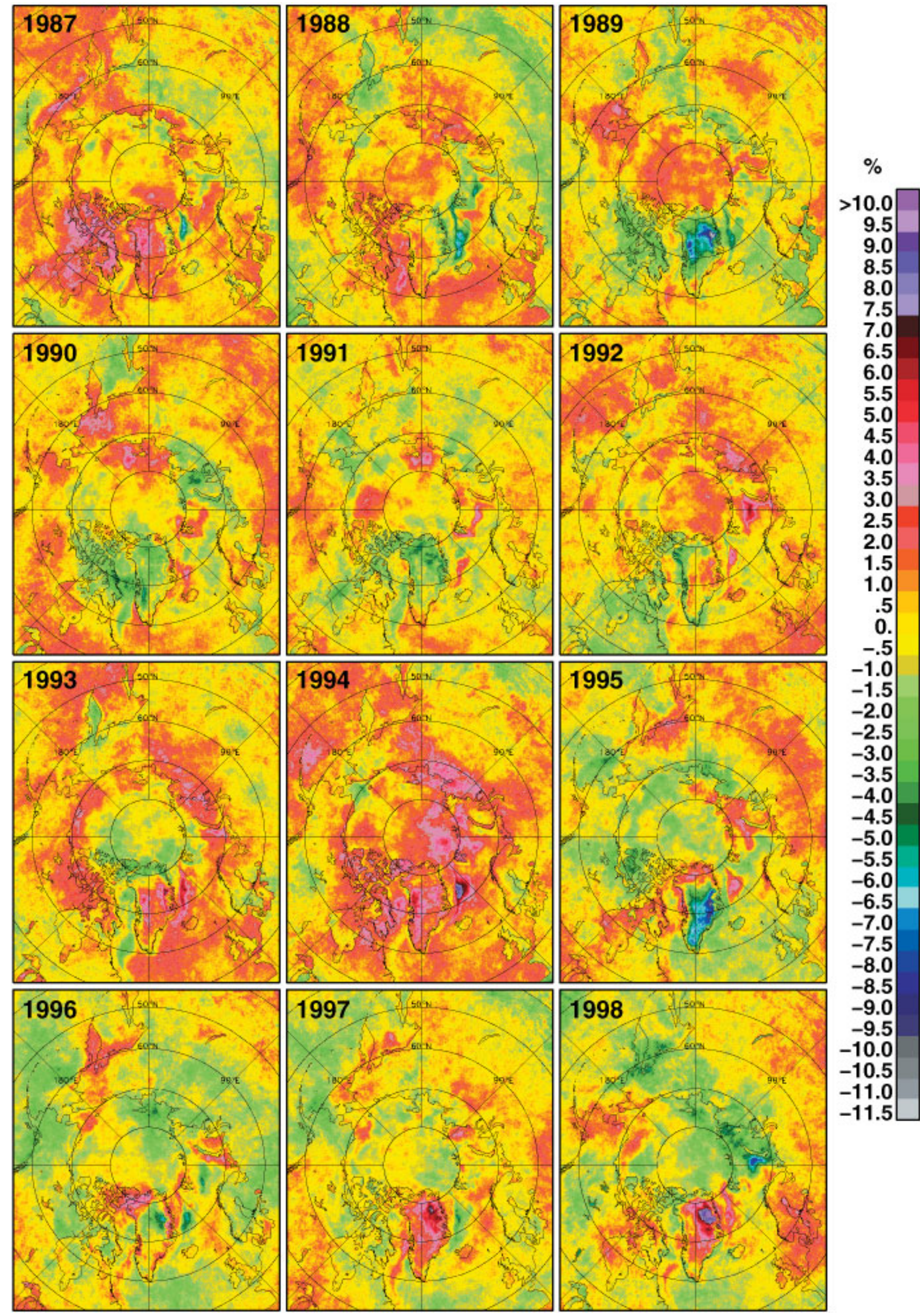

Fig. 10 Color-coded anomalies of yearly cloud-cover statistics from AVHRR in the Arctic, 1987-98. 

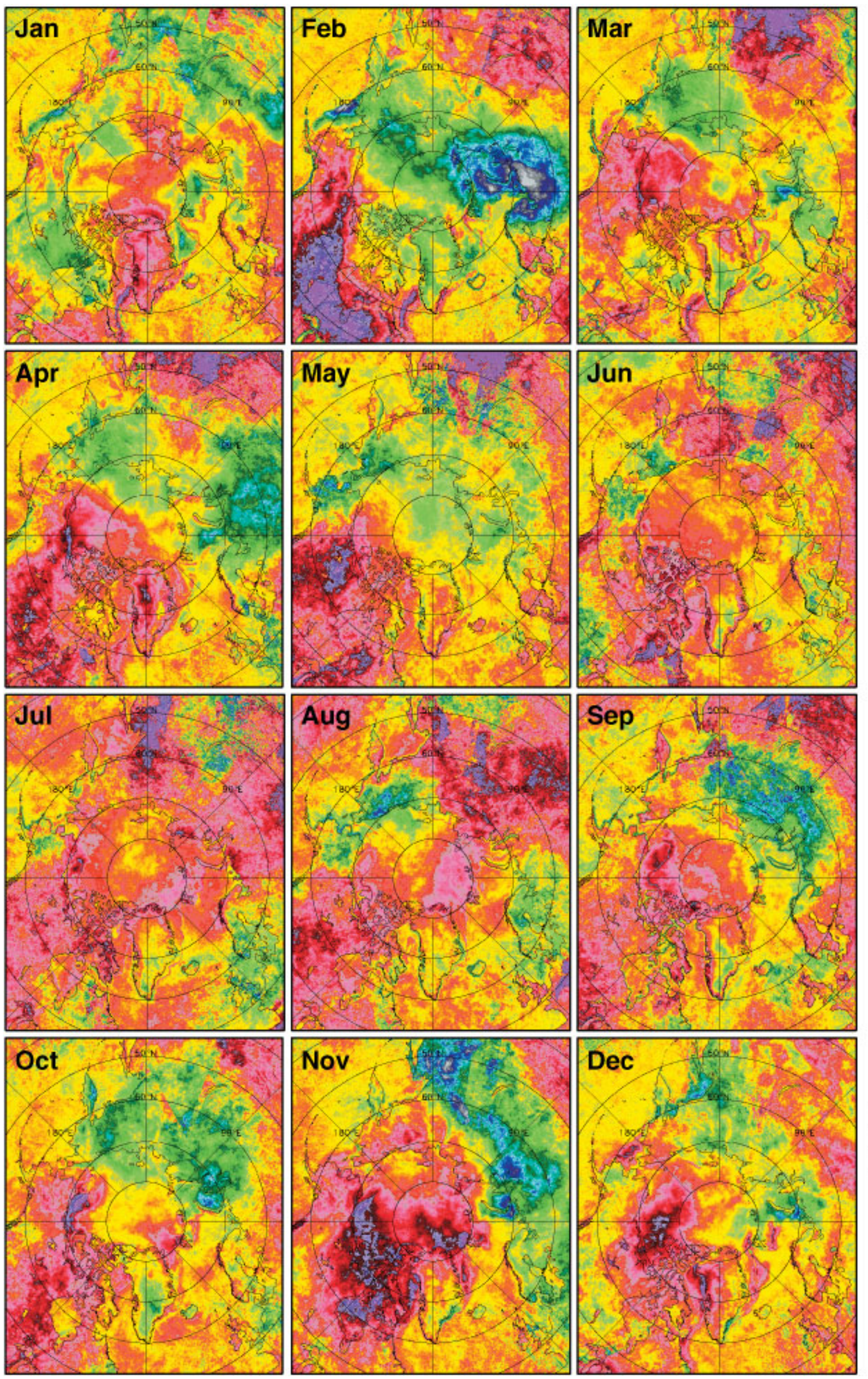

$\begin{array}{r}{ }^{\circ} \mathrm{C} \\ >10.0 \\ 9.5 \\ 9.0 \\ 8.5 \\ 8.0 \\ 7.5 \\ 7.0 \\ 6.5 \\ 6.0 \\ 5.5 \\ 5.0 \\ 4.5 \\ 4.0 \\ 3.5 \\ 3.0 \\ 2.5 \\ 2.0 \\ 1.5 \\ 1.0 \\ .5 \\ 0 . \\ -.5 \\ -1.0 \\ -1.5 \\ -2.0 \\ -2.5 \\ -3.0 \\ -3.5 \\ -4.0 \\ -4.5 \\ -5.0 \\ -5.5 \\ -6.0 \\ -6.5 \\ -7.0 \\ -7.5 \\ -8.0 \\ -8.5 \\ -9.0 \\ -9.5 \\ -10.0 \\ -10.5 \\ -11.0 \\ -11.5 \\ \hline\end{array}$

Fig. 11. Color-coded anomalies of monthly surface temperatures from AVHRR in the Arctic, January-December 1998. 
The cloud-masking technique used in this study for AVHRR data is similar to that described by Comiso (2000). It makes use of a thresholding technique that utilizes a combination of the differences of the radiances between channels 3 and 4 and between channels 4 and 5. Channel 1 is also used during daytime conditions, but the most effective technique was the use of the difference between two overlapping orbits 1 day apart, taking advantage of substantial changes in the cloud cover from one day to the next. From qualitative comparative analysis with the visible (channel 1 or 2) data, the technique is reasonably good, with an accuracy estimated at about $15 \%$ in the daily images. As pointed out earlier, the albedo maps show persistent surface features, indicating effectiveness of the cloud-identification technique.

The frequency statistics of the cloud cover in the Arctic are important to know because cloud is an integral part of the heat-budget system. Its presence or absence can also significantly alter the characteristics of the surface. The clouddetection capability provides the opportunity to study the statistics of clouds in the polar regions. The presence or absence of clouds was automatically compiled during the processing of surface data, and cloud statistics were calculated on a month-to-month basis. Since cloud classification could not be effectively done with the AVHRR data, it is possible that some types of clouds (e.g. thin clouds) were not detected by the cloud-masking technique.

The year-to-year variability of the cloud cover from 1987 to 1998 is summarized in Figure 9. The maps show, on a pixel-by-pixel basis, the percentage of the time that cloud was detected in the field of observation. The monthly images (not shown) show some seasonal characteristics and generally vary from $74 \%$ in autumn to $82 \%$ in spring. The yearly averages show less persistent cloud cover in the ice-covered ocean region than in the open-ocean region, as expected. Cloud cover is also shown to be less prominent in the northern part of Greenland and adjacent sea-ice regions.

The yearly anomaly maps, shown in Figure 10, provide a more quantitative means to evaluate interannual variability. The warm colors (oranges, pinks, and reds) correspond to abnormally cloudy areas, while the cool colors (greens and blues) correspond to abnormally cloud-free areas. The years that appear to be anomalously cloudy are 1987, 1992, 1993 and 1994, while those that are generally less cloudy than average are 1989, 1990, 1996, 1997 and 1998. However, anomalous years are not necessarily the same for different regions. In Greenland, for example, the anomalously cloudy years are 1987, 1994, 1997 and 1998, while the less cloudy years were 1989, 1990, 1991 and 1995. The patterns of anomalously cloudy areas and vice versa are also very different.

\section{CORRELATION AND TREND ANALYSES}

The yearly maps presented in the previous section provide a powerful tool for intercomparing the regional and interannual changes associated with the different geophysical variables and for evaluating possible relationships. In the Arctic sea-ice region, it is usually the case that areas of anomalously low ice concentrations correspond to areas with anomalously high temperatures and anomalously low albedo. Although Arctic clouds are known to cause surface warming, areas with anomalously persistent clouds generally do not appear to correspond to areas with warming anomalies. For example, during the period 1995-98, when the temperature- anomaly maps show the dominance of warming anomalies, the corresponding cloud-anomaly maps show fewer clouds than normal. Correlation studies of surface features with clouds is partly complicated by the unpredictable nature of the effect of the cloud cover. The effect of clouds depends on season and their characteristics, such as cloud type, height and density, which are not quantified by the AVHRR data. Also, surface albedo and temperature data correspond to cloud-free data only. However, a closer look shows reasonably good correlation of clouds with the other variables in many areas, especially in the sea-ice regions. In these regions (especially near the continental borders), areas with anomalously persistent cloud cover correspond to areas of low ice concentration and warm anomalies.

A close examination of the anomaly map in 1998 provides an example of good interrelationships between the different variables. The yearly anomaly map shows warming on the western side of the Arctic and in North America and cooling on the eastern side and in Eurasia. The warming anomalies are highly correlated with the albedo anomalies and with ice concentration where relevant. They are also well correlated in most places with the cloud-cover anomalies. The spatial scope of the possible climate signal provided by the unusual retreat in the sea-ice cover in 1998, especially in the Beaufort Sea, is strongly depicted in the temperatureanomaly map, which shows that warming was very intense not just in the vicinity of the Beaufort Sea but in a large part of the North American continent, with the highest anomaly occurring in the continental area.

The images also show large interannual variability of the albedo anomalies in the central Arctic (Fig. 8), with anomalously low values in 1989, 1990, 1991 and 1995, and high values in 1988, 1994 and 1997. Usually, the albedo is closely related to ice concentration, but in this case not much interannual change in ice concentration is observed. The change in albedo may be caused by changes in surface effects, such as snowmelt, bare ice and melt ponding, associated with warming. The surface temperature-anomaly maps show that this may indeed be the case in 1989, 1990 and 1995, but the temperature was not exceptionally warm in 1991. A possibility for 1991 is early melt in spring and/or an extended period of snow-free surface during the autumn. The lack of in situ data makes it difficult to assess the real cause, but the observation of such large interannual variations in albedo is intriguing.

The interrelationships among the variables are sometimes obscured by the use of yearly averages. For example, the effect of clouds on temperature and of temperature on the ice cover and albedo is more short-term and seasonal and may not be easy to infer from the yearly averages. The presence of large seasonal effects is manifested by large changes in the surface temperature features, as can be seen from the monthly anomaly maps shown in Figure 11. While the yearly images (Fig. 5) show a marked contrast in anomalies between North America (and the western Arctic) and Eurasia (and the eastern Arctic), the monthly maps show large changes in the areal extent and location of these anomalies from one month to another. Such changes reflect qualitatively some of the monthly changes in the cloud patterns (not shown), and in turn reflect the changes in albedo (Fig. 6). It is also interesting to note that the largest anomalies occurred in February and November, with the warm anomalies moving north to include the central Arctic region during this period. It is likely not just a coincidence that 

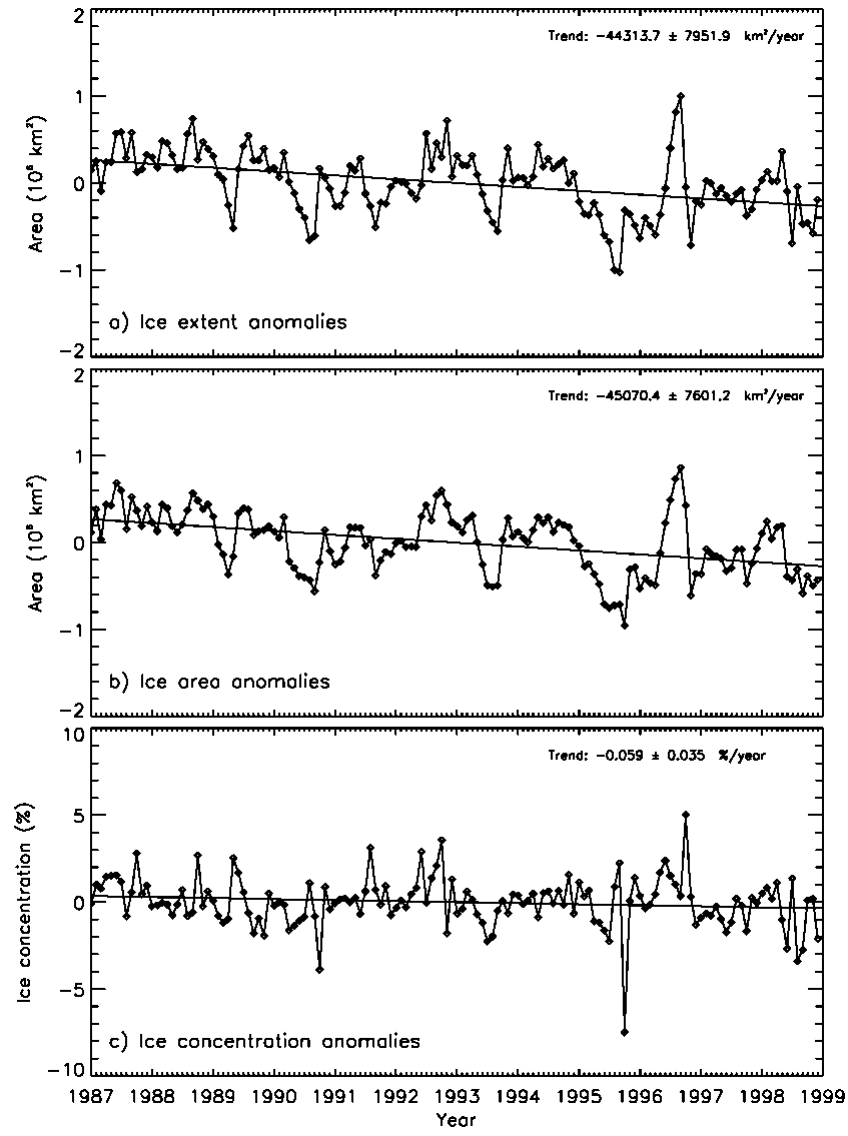

Fig. 12. Trends using anomalies in (a) ice extent, $(b)$ ice area and (c) ice concentration in the Arctic, 1987-98.

similar patterns are found in the cloud-anomaly maps (not shown) in February and November.

A question of interest is what the observed anomalies tell us about the future of the Arctic environment. Using passivemicrowave ice-concentration data from 1987 to 1998 derived using Comiso (1995), the sea-ice extent is observed to be receding at the rate of $-44300 \pm 8000 \mathrm{~km}^{2} \mathrm{a}^{-1}$ (Fig. 12a) or $-3.60 \pm 0.64 \%$ per decade. This trend is significantly higher than the $-2.19 \pm 0.28 \%$ per decade inferred for the 1979-98 period from the same dataset, and comparable to the trend of $-2.8 \pm 0.7 \%$ per decade observed by Parkinson and others (1999) and $-2.9 \pm 0.8 \%$ per decade by Bjørgo and others (1997) for the period 1979-96. The rate of decrease of the actual ice area is estimated to be $-45100 \pm 7600 \mathrm{~km}^{2} \mathrm{a}^{-1}$, or $4.19 \pm 0.71 \%$ per decade, from 1987 to 1998 (Fig. 11b), which is consistent with that of the extent, while there is a slight decrease in sea-ice concentration of $-0.059 \pm 0.035 \% \mathrm{a}^{-1}$ (Fig. 1lc). The results show significant change in the rate of decrease in the ice cover from the 20 year to 12 year record, but the record length for the latter is substantially shorter. However, the 20 year series may not be as consistently derived as the 12 year series since data from two different sensors (SMMR and SSM/I) have to be merged together. Except for the first 6 months, only SSM/I data are used in the 12 year series providing similarly derived ice-cover data.

The acceleration in the rate of decrease in the ice cover is consistent with the observed acceleration in the surface air temperature as measured from meteorological stations, as indicated earlier. Using the AVHRR surface temperature data, similar trend analysis is applied separately to the sea-icecovered areas, the Greenland ice sheet, the North American continent and the Eurasian continent (Fig. 13), and the results

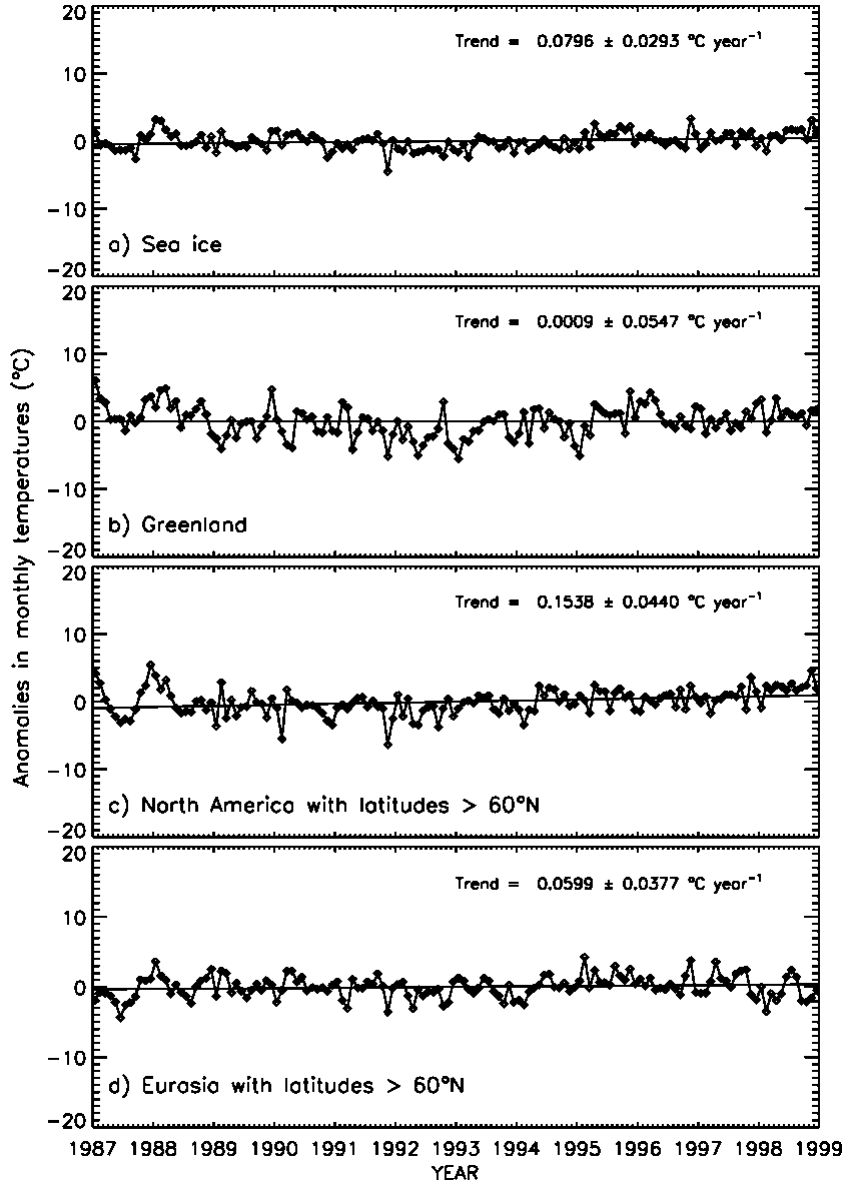

Fig. 13. Trends using anomalies in monthly surface temperature in (a) sea ice, (b) Greenland, (c) North America $\left(>60^{\circ} \mathcal{N}\right)$ and $(d)$ Eurasia $\left(>60^{\circ} \mathcal{N}\right)$.

yielded trends of $0.080 \pm 0.029^{\circ} \mathrm{Ca}^{-1}, \quad 0.001 \pm 0.055^{\circ} \mathrm{Ca}^{-1}$, $0.154 \pm 0.044^{\circ} \mathrm{Ca}^{-1}$ and $0.060 \pm 0.038^{\circ} \mathrm{Ca}^{-1}$, respectively. The trends are all positive and vary in magnitude from region to region, with the trend in North America $\left(>60^{\circ} \mathrm{N}\right)$ being quite high due mainly to the large warming anomaly in the region in 1998. The trends over sea ice and the Eurasian continent are moderate, but consistent with the trends from meteorological stations (see Fig. 3) which are practically all located in the Eurasian region, while that of Greenland is not so significant. The trend results should be interpreted with caution since the record length is short and the standard deviations of the temperature data are large, but the good consistency of satellite with the much more accurate and longer-term station data is encouraging and makes the results credible.

The yearly trend in albedo is examined by evaluating the change in surface areas with albedo $>35 \%$ for the region north of $60^{\circ} \mathrm{N}$ (Fig. 14). The results from trend analyses of monthly anomalies yielded $-18264 \pm 11812 \mathrm{~km}^{2} \mathrm{a}^{-1}, 52.7 \pm 668 \mathrm{~km}^{2} \mathrm{a}^{-1}$, $2407 \pm 6386 \mathrm{~km}^{2} \mathrm{a}^{-1}$ and $40697 \pm 12953 \mathrm{~km}^{2} \mathrm{a}^{-1}$ for sea ice, Greenland, North America and Eurasia, respectively. The trend value over sea ice is consistent but lower than that derived from ice concentration using passive-microwave data. This is partly because of interannual changes in albedo in the central Arctic (e.g. melt-pond fraction) as mentioned earlier. Practically no change in albedo is observed over Greenland, but substantial positive change is observed over the continental areas, suggesting increases in the extent of the snow cover.

The trends in cloud statistics north of $60^{\circ} \mathrm{N}$ were also 


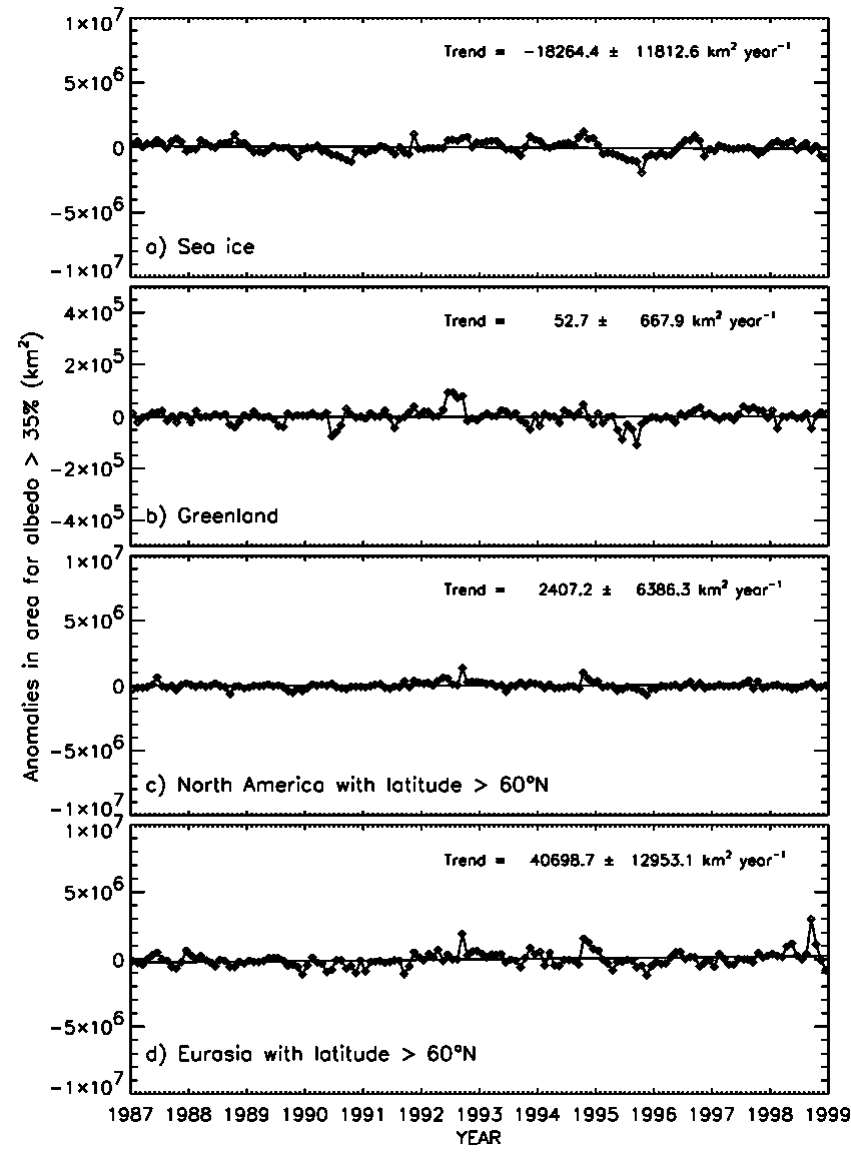

Fig. 14. Trends using anomalies in monthly albedo in (a) sea ice, (b) Greenland, (c) North America $\left(>60^{\circ} \mathcal{N}\right)$ and (d) Eurasia $\left(>60^{\circ} \mathcal{N}\right)$.

evaluated, using a cut-off of $50 \%$ in the statistics (Fig. 15), and the results yielded $-0.084 \pm 0.030 \% \mathrm{a}^{-1}, 0.152 \pm 0.067 \% \mathrm{a}^{-1}$, $-0.107 \pm 0.034 \% \mathrm{a}^{-1}$ and $-0.020 \pm 0.047 \% \mathrm{a}^{-1}$ for sea ice, Greenland, North America and Eurasia, respectively. These results indicate that the trends in cloud cover over the 12 year period were very small except perhaps over Greenland.

\section{CONCLUSIONS}

Although the record lengths of the datasets are still relatively short, satellite data provide valuable insights into the changing Arctic environment. The continuous 12 year record of surface temperature, albedo and cloud cover provided by the AVHRR sensors is a remarkable supplement to currently available ice-concentration maps derived from passive-microwave data, and significantly improves our ability to evaluate the current state of the Arctic climatology. The co-registered datasets also enable intercomparison of anomalies in the various geophysical parameters, and study of the interrelationships among these parameters.

Large warming anomalies, especially during the last four winters (i.e. 1995-98), are apparent in the data. Such warming anomalies are shown to be coherent with ice-concentration and albedo anomalies. In the sea-ice areas, the correlation of temperature with cloud cover is also good. The use of multi-parameter data allows not only for the identification and confirmation of a warming phenomenon but also for a better understanding of the spatial scope and environmental factors associated with the latter.

Large interannual changes in albedo in the central Arctic

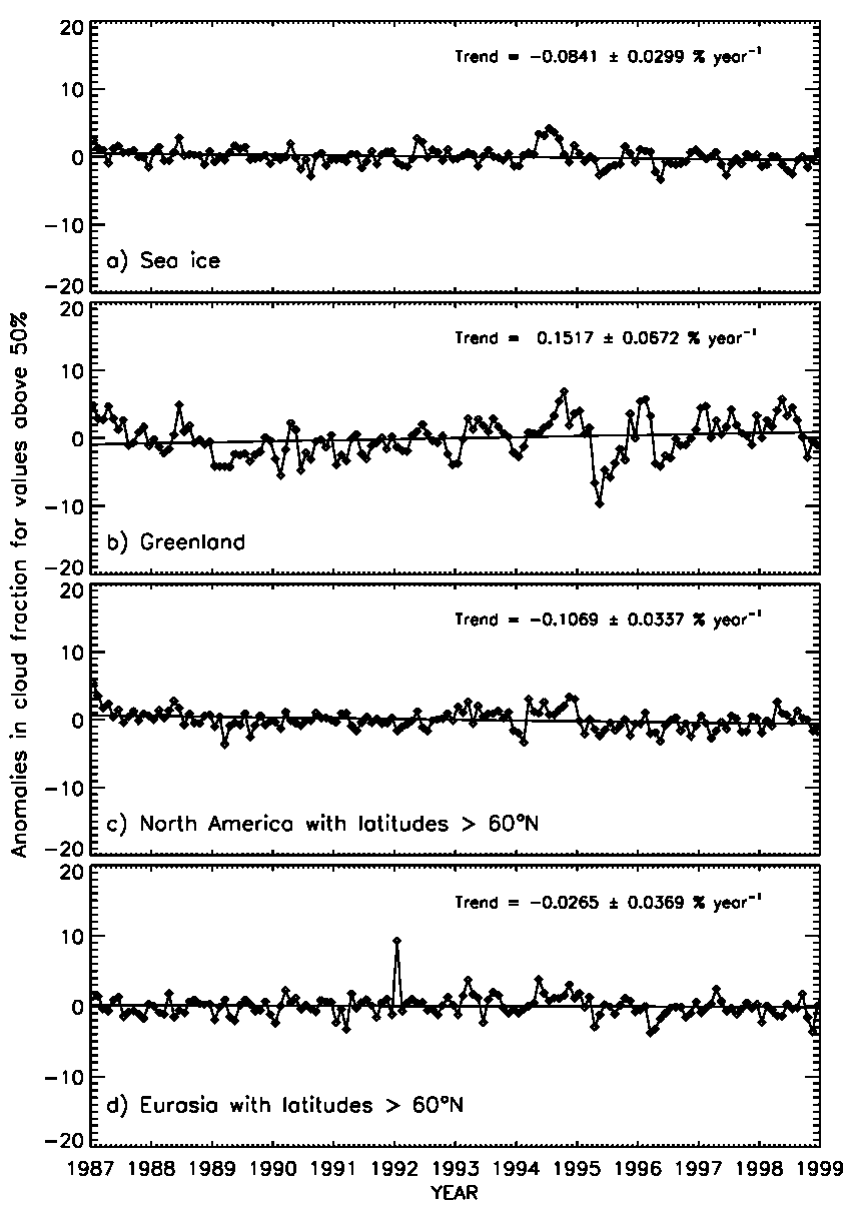

Fig. 15. Trends using anomalies in monthly cloud-cover statistics in (a) sea ice, (b) Greenland, (c) North America $\left(>60^{\circ} \mathcal{N}\right)$ and (d) Eurasia $\left(>60^{\circ} \mathcal{N}\right)$.

are also observed. Such changes indicate that even in ice areas observed to be highly consolidated during summer (Comiso and Kwok, 1996), the albedo is not constant. Such changes are likely caused by changes in the coverage and persistence of melt ponding and snow-free ice cover. Interannual changes in albedo in the continental areas are also large, reflecting large variations in the coverage and persistence of the snow cover.

The ice cover is shown to be decreasing at a faster rate when the last 12 years of data are analyzed compared to the last 20 years of data. This suggests a possible acceleration in the decrease. Such acceleration is consistent with similar acceleration in temperature derived from analysis of the much longer and relatively more accurate surface temperatures from meteorological stations. The more recent record from these stations agrees with results from the satellite temperature data. A more moderate negative rate of change is observed from the albedo data, but the record includes effects of melt ponding and barren ice.

Overall, the results reveal large changes in the Arctic environment from 1987 to 1998. To fully understand the processes leading to these changes, in-depth analyses of seasonal effects and the processing of a longer time series are needed. Analysis of changes on a season-by-season basis provides the means to assess which season is most sensitive to change. The processing of more data to produce a longer time series will enable the evaluation of the effect of cyclical atmospheric patterns, like the decadal Arctic Oscillations, that may impact the accuracy of the trend results. 


\section{ACKNOWLEDGEMENTS}

The author acknowledges the excellent programming support in the analysis of infrared and visible data provided by L. Stocks of Caelumn Inc. and in the analysis of passivemicrowave data by R. Gersten of Raytheon Corp. He is also especially grateful for many useful suggestions and comments by K. Steffen of the University of Colorado, J. Walsh of the University of Illinois and an anonymous reviewer. The work was funded by the NASA Cryosphere Program and the NASA/Earth Observing System project.

\section{REFERENCES}

Alley, R. B. 1995. Resolved: the Arctic controls global climate change. In Smith, W. O. and J. M. Grebmeier, eds. Arctic oceanography: marginal ice zones and continental shelves. Washington, DC, American Geophysical Union, 263-283. (Coastal and Estuarine Series 49.)

Allison, I., R. E. Brandt and S. G. Warren. 1993. East Antarctic sea ice: albedo, thickness distribution, and snow cover. f. Geophys. Res., 98(C7), 12,417-12,429.

Bjørgo, E., O. M. Johannessen and M.W. Miles. 1997. Analysis of merged SSMR-SSMI time series of Arctic and Antarctic sea ice parameters 1978-1995. Geophys. Res. Lett., 24(4), 413-416.

Cavalieri, D. J., P. Gloersen, C. L. Parkinson, J. C. Comiso and H. J. Zwally. 1997. Observed hemispheric asymmetry in global sea ice changes. Science, 278(5340), 1104-1106.

Chapman, W. L. and J. E. Walsh. 1993. Recent variations of sea ice and air temperature in high latitudes. Bull. Am. Meteorol. Soc., 74(1), 33-47.

Comiso, J. C. 1986. Characteristics of Arctic winter sea ice from satellite multispectral microwave observations. 7. Geophys. Res., 91(Cl), 975-994.

Comiso, J. C. 1995. SSM/I concentrations using the Bootstrap algorithm. US Nat. Aeron. Space Admin. Ref. Publ. 1380.
Comiso, J. C. 2000. Variability and trends in Antarctic surface temperatures from in situ and satellite infrared measurements. F. Climate, 13(10), 1674-1696.

Comiso, J. C. and R. Kwok. 1996. Surface and radiative characteristics of the summer Arctic sea ice cover from multi-sensor satellite observations. 7. Geophys. Res., 101 (C12), 28,397-28,416.

Francis, J. A. and A. J. Schweiger. 2000. A new window opens on the Arctic. EOS, $81(8), 77,83,96$.

Gloersen, P., W. J. Campbell, D. J. Cavalieri, J. C. Comiso, C. L. Parkinson and H. J. Zwally. 1992. Arctic and Antarctic sea ice, 1978-1987: satellite passivemicrowave observations and analysis. Washington, DC, National Aeronautics and Space Administration. (NASA SP-511.)

Jin, Z. and J. J. Simpson. 1999. Bidirectional anisotropic reflectance of snow and sea ice in AVHRR channel 1 and 2 spectral regions. Part 1. Theoretical analysis. IEEE Trans. Geosci. Remote Sensing, GE-37(1), 543-554.

Jones, P. D., M. New, D. E. Parker, S. Martin and I. G. Rigor. 1999. Surface air temperature and its changes over the past 150 years. Rev. Geophys., 37(2), 173-199.

Manabe, S., M. J. Spelman and R. J. Stouffer. 1992. Transient responses of a coupled ocean-atmosphere model to gradual changes of atmospheric $\mathrm{CO}_{2}$. Part II: Seasonal response. f. Climate, 5(2), 105-126.

Parkinson, C. L., D. J. Cavalieri, P. Gloersen, H. J. Zwally and J. C. Comiso. 1999. Arctic sea ice extents, areas, and trends, 1978-1996. F. Geophys. Res., 104(C9), 20,837-20,856.

Pfirman, S., M. A. Lange, I. Wollenburg and P. Schlosser. 1990. Sea ice characteristics and the role of sediment inclusions in deep-sea deposition: ArcticAntarctic comparisons. In Bleil, U. and J. Thiede, eds. Geological history of the polar oceans: Arctic versus Antarctic. Dordrecht, etc., Kluwer Academic Publishers, 187-211. (NATO ASI Series C: Mathematical and Physical Sciences 308.)

Rothrock, D. A., Y. Yu and G. A. Maykut. 1999. Thinning of the Arctic seaice cover. Geophys. Res. Lett., 26(23), 3469-3472.

Steffen, K. and 11 others. 1993. Snow and ice applications of AVHRR in polar regions: report of a workshop held in Boulder, Colorado, 20 May 1992. Ann. Glaciol., 17, 1-16.

Wadhams, P. 1990. Evidence for thinning of the Arctic ice cover north of Greenland. Nature, 345(6278), 795-797. 